\title{
TINTAS ANTI-INCRUSTANTES DE TERCEIRA GERAÇÃO: NOVOS BIOCIDAS NO AMBIENTE AQUÁTICO
}

\author{
Ítalo B. Castro*, Eliete Westphal e Gilberto Fillmann
}

Instituto de Oceanografia, Universidade Federal do Rio Grande, Av. Itália, km 8, 96201-900 Rio Grande - RS, Brasil

Recebido em 7/6/10; aceito em 11/1/11; publicado na web em 1/4/11

\begin{abstract}
THIRD GENERATION ANTIFOULING PAINTS: NEW BIOCIDES IN THE AQUATIC ENVIRONMENT. Antifouling agents have been used on vessels and boats since ancient civilizations. Thus, a brief history on the three generations of antifouling paints was provided in the present review. Additionally, information about physic-chemical properties, environmental levels, toxicology and analytical methods was discussed for the 16 "new" booster biocides used as third-generation antifouling paints. The main problems, limitations and future trends related to this subject were also presented. Finally, actions were suggested in order to appraise the current status of the environmental impact caused by these compounds in South America.
\end{abstract}

Keywords: antifouling; paint; booster biocides.

\section{INTRODUÇÃO}

Dentre os diversos grupos de contaminantes orgânicos potencialmente danosos a ecossistemas aquáticos, despontaram nos últimos anos os biocidas utilizados como princípio ativo de tintas antiincrustantes. Essas tintas são aplicadas como sistemas de proteção, com a finalidade de combater a formação e o estabelecimento de comunidades bioincrustantes (fouling) sobre superfícies expostas à água. Usualmente, tintas anti-incrustantes são aplicadas em embarcações comerciais e de passeio, plataformas petrolíferas, tubulações submarinas, comportas de represas, tanques destinados à aquicultura, dentre outras estruturas. ${ }^{1}$

Dentre as aplicações mencionadas para as referidas tintas, a utilização como revestimento protetor em embarcações tem sido apontada por muitos autores como a mais impactante para o ambiente, devido ao seu caráter altamente difundido em zonas costeiras. ${ }^{2}$

Segundo Kotrikla, ${ }^{3}$ o emprego de sistemas anti-incrustantes em embarcações é justificado pelos seguintes motivos: o aumento da fricção entre o casco e a água, demanda uma maior potência dos motores e, consequentemente, gera um aumento no consumo de combustível; aumento da frequência de docagens, gerando um incremento de custos e de resíduos gerados; aumento das taxas de corrosão e, introdução não intencional de espécies exóticas em ambientes aquáticos.

O primeiro registro de uso de sistemas anti-incrustantes data de 2 mil anos atrás, quando os cascos de madeira eram revestidos com chumbo e "untados" com misturas de óleo de baleia, enxofre e arsênio. Em 1625, uma receita letal combinando arsênio, cobre e goma em pó foi patenteada como agente anti-incrustante por Wilian Beale, na Inglaterra. A utilização de sistemas anti-incrustantes incorporados às tintas passou a ser comum, e cada vez mais frequente, na medida em que os cascos de madeira das embarcações foram substituídos por cascos metálicos, fato ocorrido em meados do século XVIII. A partir de então, a navegação comercial e o uso de embarcações de lazer se tornaram cada vez mais populares, aportando aos ambientes aquáticos quantidades cada vez maiores de biocidas utilizados em tintas anti-incrustantes. ${ }^{1}$

*e-mail: italo_braga@yahoo.com.br
Em meados do século XX, os óxidos de cobre e de zinco foram os primeiros biocidas utilizados regularmente em tintas anti-incrustantes ${ }^{4}$ sendo, portanto, denominados de primeira geração. ${ }^{5}$ No entanto, a durabilidade destas tintas à base de óxidos metálicos se restringia ao máximo de 1 ano após sua aplicação.

Como consequência desta rápida perda da eficiência, em 1961 foi desenvolvida a primeira tinta anti-incrustante à base de um composto organoestânico (COEs). ${ }^{6}$ Essas tintas, conhecidas como de segunda geração, ${ }^{5}$ utilizavam como princípio ativo os compostos tributilestanho (TBT) e/ou trifenilestanho (TPT). Foram amplamente empregadas e, na década de 1980, chegaram a revestir $90 \%$ dos cascos dos navios em operação no mundo. A preferência por estes anti-incrustantes se deu principalmente devido a sua grande eficiência e durabilidade. ${ }^{2}$ Devido a sua utilização, no caso de embarcações que utilizavam tintas de autopolimento, por exemplo, o período entre docagens aumentou para cerca de 7 anos. Com isso, diminuíram significativamente os custos de manutenção com as embarcações. ${ }^{2}$

Apesar da grande eficiência das tintas anti-incrustantes de segunda geração, diversos problemas relacionados à sua elevada toxicidade ambiental começaram a surgir já na década de 1980 . O primeiro caso em que se comprovou a ação tóxica dos compostos organoestânicos ocorreu em ostras da baía de Arcachon (França), uma área cercada por marinas e pequenos portos. ${ }^{7,8}$ Nesses animais foi observada uma série de efeitos deletérios, como diminuição do número de jovens recém-fixados, anomalias de desenvolvimento nas larvas e uma alteração das conchas denominada balling. Porém, o efeito biológico mais conhecido, relacionado à exposição aos COEs, é o imposex. Este fenômeno caracteriza-se pelo surgimento de estruturas sexuais secundárias masculinas em fêmeas de moluscos prosobrânquios que, por ser extremamente específico e de fácil quantificação, vem sendo utilizado mundialmente como biomarcador de áreas contaminadas por esses compostos. ${ }^{9}$

Devido a sua elevada toxicidade a espécies não alvo, a utilização de COEs em tintas anti-incrustantes foi banida pela Organização Marítima Internacional (International Maritime Organization IMO). ${ }^{2} \mathrm{O}$ processo de banimento teve início em 2003, quando foram internacionalmente proibidas novas aplicações dessas tintas. Além disso, foi estabelecido o prazo limite de setembro de 2008 para remoção desses revestimentos de estruturas em operação, bem como 
o banimento do tráfego das embarcações ainda revestidas com estas tintas à base de COEs. ${ }^{10,11}$ Por outro lado, é sabido que alguns países em desenvolvimento seguem utilizando estes compostos. ${ }^{12}$

Em razão dos problemas ambientais associados ao uso de tintas à base de organoestânicos e seu gradativo banimento mundial, uma terceira geração de tintas anti-incrustantes começou a ser utilizada a partir de 1987. Esse novo grupo de tintas contempla atualmente 16 diferentes compostos biocidas que estão homologados pela IMO para utilização em embarcações (Tabela 1). ${ }^{13}$ Estes compostos pertencem a diferentes grupos químicos e, em alguns casos, podem ser utilizados concomitantemente (até 4 deles) em uma mesma formulação comercial. ${ }^{14}$

Dentre os biocidas incorporados nos anti-incrustantes de terceira geração encontram-se compostos orgânicos não metálicos como: Diuron, Irgarol 1051, Sea-Nine, Clorotalonil, Diclofluanida, Tiram, Busan (TCMTB), TCMS Piridina e Trifenilbornano Piridina. Já os compostos metálicos (orgânicos e inorgânicos) homologados para utilização são: Zinco Piritiona, Cobre Piritiona, Ziram, Maneb, Óxido Cuproso, Tiocianato de Cobre e Naftenato de Cobre (Tabela 1).
Na maioria das tintas anti-incrustantes disponíveis no mercado mundial, esses compostos são quimicamente associados a uma matriz acrílica solúvel e atuam como biocidas ou potencializadores do efeito biocida gerado pelos metais presentes na tinta. ${ }^{2}$ Esse tipo de associação promove taxas constantes de liberação dos biocidas ao longo do tempo, elevando assim a durabilidade dos revestimentos. ${ }^{2}$

Em razão da crescente utilização destes biocidas de terceira geração, começaram a ser publicados estudos relacionando a sua ocorrência ambiental a áreas com intenso tráfego de embarcações. ${ }^{15,16}$ Entretanto, a maior parte destes estudos têm sido realizados em áreas portuárias e marinas da Europa, ${ }^{17}$ Estados Unidos da América ${ }^{18}$ e Japão, ${ }^{19}$ existindo, até o momento, somente dois estudos do gênero para a América do Sul. ${ }^{20,21}$

Sendo assim, em razão da crescente relevância do tema, o presente trabalho teve por objetivo compilar informações acerca das propriedades físico-químicas, comportamento e níveis ambientais, toxicidade, e metodologias analíticas desses 16 biocidas utilizados nas tintas anti-incrustantes de $3^{\text {a }}$ geração. Para tanto, os biocidas serão apresentados em dois grupos, conforme a presença ou não de metais na sua composição (biocidas não metálicos e metálicos).

Tabela 1. Grupo de 16 biocidas homologados pela IMO para utilização em tintas anti-incrustantes

Biocida / Nome comercial

(Nome químico / CAS)

Estrutura

\section{Não metálicos}

Irgarol 1051

(2-metiltio-4-terc-butilamino-6ciclopropilamino-s-triazina)

$\mathrm{N}^{\circ}$ CAS 28159-98-0

Diuron

(3-(3,4-Diclorofenil)-1,1-dimetilurea) $\mathrm{N}^{\circ}$ CAS 330-54-1

DCOIT

(4,5-Dicloro-2-n-octil-4- isotiazolin3-ona)

No CAS 64359-81-5

Clorotalonil

(2,4,5,6 Tetracloroisoftalonitrila) $\mathrm{N}^{\circ}$ CAS 1897-45-6

Diclofluanida

(N,N-Dimetil-N-fenil-N(diclorofluorometiltio)sulfamida) $\mathrm{N}^{\circ}$ CAS 1085-98-9

Tiram

(Tetrametiltiuramdissulfida)

$\mathrm{N}^{\circ}$ CAS 137-26-8

TCMTB / Busan

(2-(tiocianometiltio) benzotiazol)

$\mathrm{N}^{\circ}$ CAS 21564-17-0

TCMS Piridina / Densil

((2,3,3,6-tetracloro-4-metilsulfonil) piridina)

№ CAS 13108-52-6

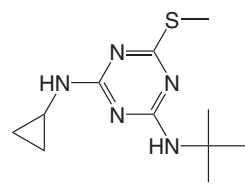<smiles>CN(C)C(=O)Nc1ccc(Cl)c(Cl)c1</smiles><smiles>CCCCCCCCn1sc(Cl)c(Cl)c1=O</smiles><smiles>N#Cc1c(Cl)c(Cl)c(Cl)c(C#N)c1Cl</smiles>

$$
\mathrm{Cl} \mathrm{Cl}^{\mathrm{Cl}}
$$

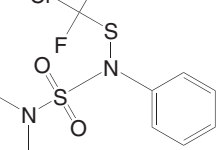

$\prod_{\mathrm{S}}^{\mathrm{N}} \mathrm{s}_{\mathrm{S}}^{\mathrm{N}^{\prime}} \overbrace{\mathrm{s}}$
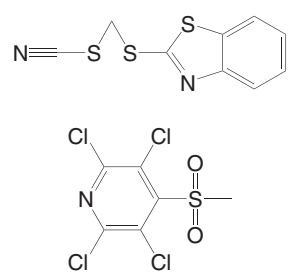

Biocida / Nome comercial

(Nome químico / CAS)

Estrutura

Trifenilborano Piridina / TPBP

$\mathrm{N}^{\circ}$ CAS 971-66-4

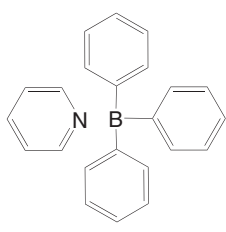

\section{Metálicos}

Cobre Piritiona / CP

(Cobre,bis(1,hidroxi-2(1H)-piridinationato $\mathrm{O}, \mathrm{S})$ )

$\mathrm{N}^{\circ}$ CAS 14915-37-8

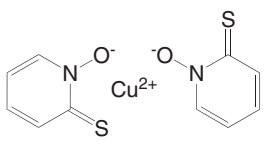

Zinco Piritiona / ZP

(Zinco, bis-(hidroxi-2(1H)-piridina-

tionato-O,S))

$\mathrm{N}^{\circ}$ CAS 13463-41-7

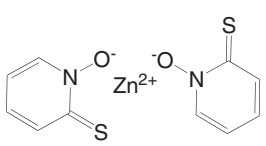

Ziram

(Zinco dimetilditiocarbamato)

$\mathrm{N}^{\circ}$ CAS 137-30-4

$$
\int_{\mathrm{S}}^{\mathrm{N}} \mathrm{Zn}^{2+} \gamma^{-\mathrm{S}} \mathrm{S}
$$

Maneb

(Manganesetileno

bis(ditiocarbamato) (polimérico))

$\mathrm{N}^{\circ}$ CAS 12427-38-2

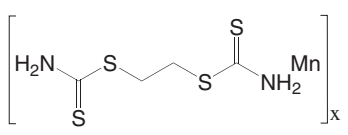

Óxido cuproso

CAS 1317-39-1

$$
{ }^{{ }^{+} \mathrm{Cu}^{+}} \stackrel{\mathrm{O}^{2-}}{\mathrm{Cu}^{+}}=\mathrm{N}
$$

Tiocianato de cobre

$\mathrm{N}^{\circ}$ CAS 1111-67-7

Naftenato de cobre

No CAS 1338-02-9

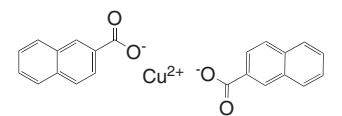




\section{BIOCIDAS NÃO METÁLICOS}

\section{Irgarol 1051}

O Irgarol 1051 (2-metiltio-4-terc-butilamino-6-ciclopropilamino$s$-triazina) é um composto pertencente ao grupo das triazinas que apresenta solubilidade moderada em água ( $7 \mathrm{mg} / \mathrm{L})$, coeficiente de partição octanol/água $\left(\log \mathrm{K}_{\mathrm{ow}}\right)$ de 3,95 e baixa taxa de degradação nessa matriz (Tabela 2). Estudos demonstraram que esse composto permanece intacto por períodos de até 36 dias em amostras de água e que particiona preferencialmente nos sedimentos. ${ }^{22}$ Após esse período, o Irgarol 1051 pode ser hidrolisado em diferentes metabólitos: M1(2-metiltio-4-terc-butilamino-6-amino-s-triazina), M2(2-amino-propanal-4-terc-butilamino-6-metiltio-s-triazina) e M3(2,4(diamino-di-terc-butil)-6-metiltio-s-triazina). Apesar do M1 ser o metabólito preferencialmente formado, as suas concentrações ambientais (ex.: marinas) são normalmente mais baixas do que o Irgarol. ${ }^{23}$ Isso sugere que a taxa de transformação de Irgarol a M1 é relativamente lenta e/ou que a taxa de degradação deste metabólito é maior do que a de sua formação. ${ }^{24}$

Em sedimentos, a degradação do Irgarol é lenta mesmo sob condições aeróbias, com tempos de meia vida de 100 e 200 dias para os sedimentos marinhos e de água doce, respectivamente. Essas taxas são consideravelmente mais lentas em condições anaeróbias. ${ }^{25}$

O Irgarol é o biocida utilizado em anti-incrustantes mais frequentemente detectado no mundo, tendo sido primeiramente reportado como contaminante aquático em 1993, na Cote d'Azur (França). ${ }^{26}$ Estudos em águas costeiras e continentais indicam uma ocorrência bastante difundida nesses ambientes. ${ }^{27}$ Estudos realizados nos Estados Unidos, Europa e Ásia têm demonstrado elevadas concentrações desse composto em amostras de água, com valores de até 1.300 ng/L nas Ilhas Virgens, 1.700 ng/L na Cote d'Azur e 4.200 ng/L em Singapura. ${ }^{18,28,29}$ Também tem sido reportada a ocorrência ambiental do metabólito M1 com concentrações variando entre 1 e 4.000 ng/L em amostras de água oriundas de marinas da Ásia, Europa e Estados Unidos. ${ }^{30-32}$

A ocorrência de Irgarol 1051 em amostras de água do mar tem sido globalmente relacionada a áreas onde se observa fluxo de embarcações, sobretudo em marinas e portos pesqueiros. Zonas exclusivamente portuárias (onde trafegam embarcações de grande porte) têm apresentado concentrações proporcionalmente mais baixas quando compradas a essas áreas. ${ }^{33}$ Adicionalmente, os níveis de Irgarol variam sazonalmente conforme as atividades náuticas na Europa, evidenciando a ampla utilização deste composto em tintas anti-incrustantes aplicadas a embarcações de pequeno porte. ${ }^{34}$ No Brasil, determinações realizadas em amostras de água do Rio Paraíba do $\mathrm{Sul}^{21}$ e do canal do São Gonçalo ${ }^{20}$ revelaram níveis extremamente baixos, porém detectáveis, de Irgarol. Em ambas as áreas foi observada a presença de tráfego de embarcações.

Alguns estudos conduzidos com amostras de sedimentos obtidas em portos e marinas encontraram valores de Irgarol de até $113 \mathrm{ng} / \mathrm{g}$ na baía de Otsuchi (Japão), ${ }^{19} 220$ ng/g no mar Báltico e 1.011 ng/g no estuário Blackwater (Reino Unido). ${ }^{18,35}$ No Brasil, níveis de concentração variando entre 0,2 e $5,8 \mathrm{ng} / \mathrm{g}$ foram detectados em amostras de sedimentos obtidos em uma zona portuária localizada no estuário da Lagoa dos Patos, Rio Grande do Sul. ${ }^{36}$

Tabela 2. Principais propriedades físico-químicas dos 16 biocidas usados em anti-incrustantes de terceira geração (S.A., solubilidade em água; M.M., massa molecular; P.V., pressão de vapor; P.E., ponto de ebulição)

\begin{tabular}{|c|c|c|c|c|c|}
\hline Biocida & $\log \mathrm{K}_{\mathrm{ow}}$ & S.A. $(\mathrm{mg} / \mathrm{L})$ & M.M. & P.V. (Pa) & P.E. $\left({ }^{\circ} \mathrm{C}\right)$ \\
\hline \multicolumn{6}{|l|}{ Não metálicos } \\
\hline Irgarol 1051 & 3,95 & 7 & 253,4 & $1,5 \times 10^{-5}$ & 428,0 \\
\hline Diuron & 2,85 & 36,4 & 233,1 & $4,1 \times 10^{-4}$ & 385,2 \\
\hline DCOIT & 2,85 & 0,0065 & 213,3 & $4,0 \times 10^{-4}$ & 322,6 \\
\hline Clorotalonil & 2,64 & 0,6 & 265,9 & $1,3 \times 10^{-5}$ & 350,5 \\
\hline Diclofluanida & 3,70 & 0,006 & 333,2 & $1,3 \times 10^{-4}$ & 336,8 \\
\hline Tiram & 1,70 & 30,0 & 240,4 & $\mathrm{NE}$ & 307,4 \\
\hline ТСМТВ & 3,30 & 45,0 & 238,4 & 1,0 & NA \\
\hline TCMS Piridina & NE & 0,025 & 294,9 & NE & 451,1 \\
\hline Trifenilborano Piridina & NE & 1,0 & 321,2 & $1,3 \times 10^{-4}$ & 348,0 \\
\hline \multicolumn{6}{|l|}{ Metálicos } \\
\hline Cobre Piritiona & 0,97 & $<1$ & 315,9 & $\mathrm{NE}$ & 253,8 \\
\hline Zinco Piritiona & 0,97 & 6,0 & 317,7 & $1,33 \times 10^{-4}$ & 262,0 \\
\hline Ziram & 1,23 & 17,0 & 305,8 & $\mathrm{NE}$ & 248,0 \\
\hline Maneb & NE & 6,0 & 265,3 & $\mathrm{NE}$ & 308,2 \\
\hline Óxido cuproso & $\mathrm{NE}$ & $\mathrm{NE}$ & 145,1 & $\mathrm{NE}$ & 1800,0 \\
\hline Tiocianato de cobre & $\mathrm{NE}$ & $\mathrm{NE}$ & 179,7 & $\mathrm{NE}$ & 146,0 \\
\hline Naftenato de cobre & $\mathrm{NE}$ & $\mathrm{NE}$ & 405,9 & NE & 250,0 \\
\hline
\end{tabular}

Dados obtidos das refs. 27, 60, 75, 89 e 95; NE: dados não encontrados na literatura; NA: não aplicável, visto que esse composto se decompõe abaixo do ponto de ebulição. 
O Irgarol 1051 é um potente inibidor da atividade fotossintética, atuando principalmente sobre o fotossistema II. Esse composto promove a inibição da fixação de carbono, provocando uma redução na produção de carboidratos por seres autotróficos. ${ }^{37}$ Desta forma, seu efeito é mais pronunciado em organismos fitoplanctônicos. ${ }^{38}$ Esse fato tem sido confirmado por testes de toxicidade, onde foi verificado, por exemplo, uma $\mathrm{CE}_{50}(120 \mathrm{~h}) \mathrm{de} 0,43 \mu \mathrm{g} / \mathrm{L}$ para a diatomácea Skeletonema costatum e de $0,56 \mu \mathrm{g} / \mathrm{L}$ para a clorofícea Dunaliella tertiolecta. Já para espécies de peixe, como Menidia beryllina e Cyprinodon variegatus, os valores de $\mathrm{CL}_{50}(96 \mathrm{~h}$ ) foram de 1.580 e $3.500 \mu \mathrm{g} / \mathrm{L}$, respectivamente. Adicionalmente, testes ecotoxicológicos realizados no Brasil com as espécies de crustáceos Acartia tonsa (48 h), Mysidopsis juniae (96 h) e Kalliapseudes schubartii (96 h) resultaram em valores de $\mathrm{CL}_{50}$ de 714,310 e $5600 \mu \mathrm{g} / \mathrm{L}$, respectivamente (Tabela 3 ). ${ }^{39}$

A determinação de Irgarol 1051 em níveis traço tem sido realizada por diferentes métodos analíticos. Este analito é normalmente extraído de matrizes aquosas por métodos que empregam a extração em fase sólida (EFS) ou extração líquido-líquido (ELL). ${ }^{40}$ Para matrizes sólidas, como o sedimento, os métodos de extração mais aplicados utilizam Soxhlet ou sonificação. ${ }^{15}$ Já a quantificação pode ser feita por cromatografia a gás com detector de espectrometria de massas (CG/EM), cromatografia de fase líquida de alta eficiência com de-

Tabela 3. Toxicicade de biocidas utilizados em tintas anti-incrustantes de terceira geração sobre diversos grupos de organismos. (CE, concentração efetiva, CL concentração letal)

\begin{tabular}{|c|c|c|c|c|}
\hline Biocida & Grupo & Espécie & Efeito (tempo) & Concentração $(\mu \mathrm{g} / \mathrm{L})$ \\
\hline \multirow[t]{7}{*}{ Irgarol 1051} & Alga & Skeletonema costatum & $\mathrm{CE}_{50}(120 \mathrm{~h})$ & 0,43 \\
\hline & & Dunaliella tertiolecta & & 0,56 \\
\hline & Peixe & Menidia beryllina & $\mathrm{CL}_{50}(96 \mathrm{~h})$ & 1.580 \\
\hline & & Cyprinodon variegatus & & 3.500 \\
\hline & Crustáceo & Acartia tonsa & $\mathrm{CL}_{50}(48 \mathrm{~h})$ & 714 \\
\hline & & Mysidopsis juniae & $\mathrm{CL}_{50}(96 \mathrm{~h})$ & 310 \\
\hline & & Kalliapseudes schubartii & & 5600 \\
\hline \multirow[t]{8}{*}{ Diuron } & Alga & Chaetoceros gracilis & $\mathrm{CE}_{50}(72 \mathrm{~h})$ & 36,0 \\
\hline & & Dunaliella tertiolecta & $\mathrm{CE}_{50}(96 \mathrm{~h})$ & 0,7 \\
\hline & Crustáceo & Artemia salina & $\mathrm{CE}_{50}(24 \mathrm{~h})$ & 3.011 \\
\hline & & Acartia tonsa & $\mathrm{CL}_{50}(48 \mathrm{~h})$ & 1.486 \\
\hline & & Mysidopsis juniae & $\mathrm{CL}_{50}(96 \mathrm{~h})$ & 589 \\
\hline & & Kalliapseudes schubartii & & 7.560 \\
\hline & Ouriço & Paracentrotus lividus, & $\mathrm{CE}_{50}(48 \mathrm{~h})$ & 2.390 \\
\hline & & Lytechinus variegatus & $\mathrm{CE}_{50}(24 \mathrm{~h})$ & 3.335 \\
\hline \multirow[t]{2}{*}{ DCOIT } & Alga & Skeletonema costatum & $\mathrm{CL}_{50}(96 \mathrm{~h})$ & 13,9 \\
\hline & Peixe & Cyprinodon variegatus & & 20,5 \\
\hline \multirow[t]{2}{*}{ Clorotalonil } & Alga & Dunaliella tertiolecta & $\mathrm{CE}_{50}(96 \mathrm{~h})$ & 64,0 \\
\hline & Peixe & Pimephales promelas & $\mathrm{CL}_{50}(96 \mathrm{~h})$ & 22,6 \\
\hline \multirow[t]{6}{*}{ Diclofluanida } & Bactéria & Vibrio fisheri & $\mathrm{CE}_{50}(15 \mathrm{~min})$ & 15,7 \\
\hline & Alga & Selenastrum capricornotum & $\mathrm{CE}_{50}(72 \mathrm{~h})$ & 21 \\
\hline & Crustáceo & Daphnia magna & $\mathrm{CE}_{50}(48 \mathrm{~h})$ & 1.330 \\
\hline & Molusco & Mytulis edulis & & 81 \\
\hline & Ouriço & Paracentrotus lividus & & 627 \\
\hline & Nematódeo & Ciona intestinalis & $\mathrm{CE}_{50}(24 \mathrm{~h})$ & 283 \\
\hline \multirow[t]{3}{*}{ Tiram } & Alga & Chlorella pyrenoidosa & $\mathrm{CE}_{50}(96 \mathrm{~h})$ & 1.000 \\
\hline & Crustáceo & Daphnia magna & $\mathrm{CL}_{50}(48 \mathrm{~h})$ & 210 \\
\hline & Peixe & Oncorhyncus mykiss & $\mathrm{CE}_{50}(60$ dias $)$ & 0,64 \\
\hline \multirow[t]{3}{*}{ ТСМТВ } & Bactéria & Vibrio fisheri & $\mathrm{CE}_{50}(15 \mathrm{~min})$ & 58,0 \\
\hline & Alga & Selenastrum capricornotum & $\mathrm{CE}_{50}(30 \mathrm{~h})$ & 7,8 \\
\hline & Crustáceo & Daphnia magna & $\mathrm{CE}_{50}(48 \mathrm{~h})$ & 6,8 \\
\hline \multirow[t]{2}{*}{ ТРВP } & Alga & Skeletonema costatum & $\mathrm{CL}_{50}(72 \mathrm{~h})$ & 2,2 \\
\hline & Crustáceo & Artemia salina & & 130 \\
\hline Piritionas Metálicas & Crustáceo & Várias espécies & $\mathrm{CL}_{50}$ & $>100$ \\
\hline \multirow[t]{2}{*}{ Ziram } & Alga & Chlorella pyrenoidosa & $\mathrm{CE}_{50}(96 \mathrm{~h})$ & 1.200 \\
\hline & Peixe & Oncorhynchus mykiss & $\mathrm{CE}_{50}(60$ dias $)$ & 1,5 \\
\hline
\end{tabular}


tector de arranjo de diodos (CLAE/DAD) ou cromatografia líquida com detector de espectrometria de massas (CL/EM). Entretanto, a separação do Irgarol dos seus metabólitos apresenta uma melhor resolução por cromatografia líquida com ionização química à pressão atmosférica (CL/IQPA/EM). ${ }^{41}$

\section{Diuron}

O Diuron (3-(3,4-diclorofenil)-1,1-dimetilurea) é um herbicida do grupo das fenilureias que vem sendo utilizado na agricultura desde 1950, ${ }^{1}$ sendo empregado em tintas anti-incrustantes a partir da década de $1980 .{ }^{42}$ É um composto não iônico, com moderada solubilidade em água $(36,4 \mathrm{mg} / \mathrm{L})$ e coeficiente de partição octanol/ água $\left(\log \mathrm{K}_{\mathrm{ow}}\right)$ de 2,85 (Tabela 2). Esse composto é estável à oxidação e atua como inibidor da fotossíntese em diversas espécies. ${ }^{29}$ Sua taxa de hidrólise é insignificante em um pH neutro, mas aumenta sob circunstâncias fortemente ácidas ou alcalinas. Estudos experimentais demonstram que sua meia vida em ambiente aquático encontra-se entre 14 e 27 dias. ${ }^{18}$

Apesar do seu uso na agricultura, concentrações mais elevadas de Diuron em água do mar que as observadas em águas doces indicam que a sua fonte está relacionada à utilização como agente anti-incrustante..$^{43}$ Elevadas concentrações associadas ao seu uso em tintas anti-incrustantes têm sido encontradas em amostras de água obtidas em marinas na Europa, as quais apresentam seus picos nos períodos em que as embarcações de lazer estão sendo utilizadas. ${ }^{44}$ Valores de até $6.742,2.000$ e $1.130 \mathrm{ng} / \mathrm{L}$ foram encontrados em águas da baía de Southampton (Inglaterra) ${ }^{45}$ em marinas na região costeira da Catalúnia (Espanha) ${ }^{32}$ e na costa da Holanda, ${ }^{44}$ respectivamente. Tais resultados são provavelmente consequência do grande fluxo de embarcações nessas regiões. Situação similar foi observada também em estudos na Inglaterra, Suécia, Portugal e Japão. ${ }^{46}$ No Brasil, foram verificadas concentrações detectáveis (até $20,9 \mathrm{ng} / \mathrm{g}$ ) de Diuron em amostras de água e sedimentos oriundas de áreas sob a influência dos terminais portuários localizados no interior do estuário da Lagoa dos Patos (Rio Grande, RS). ${ }^{36}$

Assim como o Irgarol 1051, o Diuron costuma apresentar toxicidade extremamente elevada para organismos fitoplanctônicos, tais como a diatomácea Chaetoceros gracilis $\left(\mathrm{CE}_{50}(72 \mathrm{~h})=36,0\right.$ $\mu \mathrm{g} / \mathrm{L})$ e a clorofícea $D$. tertiolecta $\left(\mathrm{CE}_{50}(96 \mathrm{~h})=0,7 \mu \mathrm{g} / \mathrm{L}\right) .{ }^{47} \mathrm{Em}$ contrapartida, apresenta níveis inferiores de toxicidade para invertebrados, como os observados para os microcrustáceos Artemia salina $\left(\mathrm{CE}_{50}(24 \mathrm{~h})=3.011 \mu \mathrm{g} / \mathrm{L}\right),{ }^{47}$ Acartia tonsa $\left(\mathrm{CL}_{50}(48 \mathrm{~h})\right.$ $=1.486 \mu \mathrm{g} / \mathrm{L}),{ }^{39}$ Mysidopsis juniae $\left(\mathrm{CL}_{50}(96 \mathrm{~h})=589 \mu \mathrm{g} / \mathrm{L}\right)^{39} \mathrm{e}$ Kalliapseudes schubartii $\left(\mathrm{CL}_{50} 96 \mathrm{~h}=7.560 \mu \mathrm{g} / \mathrm{L}\right) .{ }^{39}$ Adicionalmente, em testes de toxicidade visando verificar a embriotoxicidade do Diuron sobre a espécie de ouriço Paracentrotus lividus, a $\mathrm{CE}_{50}$ (48 h) obtida foi de $2.390 \mu \mathrm{g} / \mathrm{L} \cdot{ }^{47,48}$ Similarmente para espécie de ouriço Lytechinus variegatus os valores de $\mathrm{CE}_{50}(24 \mathrm{~h})$ obtidos foram de $3335 \mu \mathrm{g} / \mathrm{L} .{ }^{39}$ Esses resultados refletem o fato do Diuron ter sido inicialmente desenvolvido para o combate de ervas daninhas, tendo seu mecanismo de atuação associado à inibição do fluxo de elétrons necessários a realização da fotossíntese nos organismos autotróficos (Tabela 3). ${ }^{47}$

O Diuron tem sido normalmente analisado a partir de matrizes aquosas utilizando EFS, enquanto que a técnica mais frequentemente empregada para sedimentos é a agitação mecânica da amostra em solventes orgânicos, como acetonitrila. ${ }^{49} \mathrm{~A}$ identificação e quantificação é feita por cromatografia líquida com detecção por espectrometria de massas (CL/EM), podendo também ser utilizada a cromatografia a gás com detector de espectrometria de massas (CG/EM). Neste último caso, é necessária uma etapa prévia de derivatização por alquilação com iodometano. ${ }^{40,50}$

\section{DCOIT (Sea-Nine 211)}

O Sea-Nine 211 é uma mistura comercial que possui $30 \%$ do ingrediente ativo (4,5-Dicloro-2-n-octil-4-isotiazolin-3-ona ou DCOIT) em xileno. Esse biocida, é um isotiazol que foi inicialmente sintetizado pela empresa Rohm and Haas, em 1992, tendo sido homologado para utilização como agente anti-incrustante pela IMO e recebido registro de utilização pela Agência de Proteção Ambiental dos Estados Unidos (USEPA) em 1994. ${ }^{51}$ Com respeito às características físico-químicas, o DCOIT possui baixa solubilidade em água $(0,0065$ $\mathrm{mg} / \mathrm{L}$ ), um $\mathrm{K}_{\text {ow }}$ de 2,85 e uma rápida taxa de degradação na água do mar (meia vida de aproximadamente $1 \mathrm{~h}$ ). ${ }^{52}$ Adicionalmente, forma complexos extremamente estáveis com os sedimentos, tornandose pouco biodisponível e, consequentemente, apresenta um baixo fator de bioacumulação para organismos aquáticos. A degradação do DCOIT ocorre normalmente pela abertura da porção cíclica da molécula, o que reduz a toxicidade de seus subprodutos numa ordem de magnitude de 4 a 5 vezes. Em água do mar e nos sedimentos, a degradação acontece, sobretudo, pela ação de micro-organismos, sendo pouco significativa a contribuição dos processos de hidrólise e de fotólise para essa transformação. ${ }^{51}$ Desta forma, o Sea-Nine vem sendo considerado o agente anti-incrustante que apresenta menores danos ambientais. ${ }^{51,52}$

Os poucos estudos existentes apontam para níveis ambientais baixos. Segundo Harino et al., ${ }^{19}$ o DCOIT está entre os biocidas utilizados em anti-incrustantes de terceira geração detectados em menores níveis em amostras obtidas no litoral japonês. As concentrações detectadas variaram entre 2 e $28 \mathrm{ng} / \mathrm{L}$ no porto de Osaka e baías Maizuru e Hiroshima. ${ }^{19}$ Já no litoral da Grécia foram detectados valores de até $49 \mathrm{ng} / \mathrm{L},{ }^{53}$ não sendo detectado entretanto em amostras de água da baía de Southampton (Inglaterra). ${ }^{24}$

Toxicologicamente, o DCOIT demonstra elevada atividade antimicrobiana, sobretudo com relação a bactérias, fungos e algas. ${ }^{29}$ Diferentemente do Diuron e do Irgarol 1051, os seus níveis de toxicidade para espécies do fitoplâncton e do zooplâncton são muito parecidos. Visto que em testes realizados com a diatomácea Skeletonema costatum e com o peixe Cyprinodon variegatus, os valores de $\mathrm{CL}_{50}(96 \mathrm{~h}$ ) foram 13,9 e 20,5 $\mu \mathrm{g} / \mathrm{L}$, respectivamente (Tabela 3).

Os métodos analíticos aplicados para determinação do DCOIT em amostras de água são, em sua maioria, a EFS e a microextração em fase sólida (MEFS).${ }^{54}$ Amostras de sedimentos são normalmente extraídas a partir de agitação mecânica com solventes orgânicos, como acetonitrila. ${ }^{49} \mathrm{~A}$ identificação e quantificação deste biocida são normalmente realizadas através de cromatografia líquida (CL/EM), podendo também ser realizada por cromatografia a gás com detecção por espectrometria de massas $(\mathrm{CG} / \mathrm{EM})^{55}$ ou detector de captura de elétrons (CG/DCE). ${ }^{41}$

\section{Clorotalonil}

O Clorotalonil (2,4,5,6-tetracloroisoftalonitrila) é um organoclorado do grupo das isoftalonitrilas, que é utilizado há mais de 30 anos como fungicida na agricultura mundial. ${ }^{27}$ Sua utilização como biocida ativo em tintas anti-incrustantes iniciou após o banimento das tintas à base de organoestânicos. ${ }^{26}$ Esse composto apresenta um $\mathrm{K}_{\text {ow }}$ de 2,64 (Tabela 2), uma baixa solubilidade em água ( $0,6 \mathrm{mg} / \mathrm{L})$ e é extremamente susceptível à fotodegradação. Devido a essas características, apresenta uma meia vida de até 4 semanas em meio aquático. Sua fotodegradação pode ser ainda mais rápida dependendo da natureza do corpo d'água e de fatores como a concentração de material orgânico, como ácidos húmicos e fúlvicos ${ }^{53}$ Estudos conduzidos por Walker $e t$ $a l .{ }^{56}$ demonstraram que a degradação do Clorotalonil é mais rápida em água estuarina e marinha do que em água esterilizada, sugerindo 
também uma contribuição microbiana nos processos de degradação desse composto. Em sedimentos, a meia vida do Clorotalonil costuma ser maior do que em água, apresentando persistência de até 3 meses. ${ }^{27,57}$ Quanto ao seu equilíbrio sortivo, estudos demonstraram que em $\mathrm{pH} 8$ o Clorotalonil costuma se adsorver ao material particulado. ${ }^{27}$

De acordo com os resultados obtidos por diversos estudos, a ocorrência ambiental de Clorotalonil não segue o mesmo padrão de distribuição dos demais biocidas utilizados em formulações de tintas anti-incrustantes. Devido ao seu uso agrícola ser bastante difundido, ${ }^{46}$ sendo frequentemente detectado em solos plantados, poucos estudos relacionam a presença de Clorotalonil à utilização em tintas anti-incrustantes. Em função de suas propriedades físico-químicas, baixas concentrações desse composto têm sido detectadas na coluna d'água. Estudos realizados na Europa encontraram valores de Clorotalonil abaixo dos níveis de detecção das técnicas empregadas, ${ }^{15,53,58}$ sendo os maiores valores reportados para algumas marinas da Grécia ( $\leq 120 \mathrm{ng} / \mathrm{L})$ e para o estuário Blackwater (Inglaterra) $(\leq 1.380 \mathrm{ng} / \mathrm{L})$. Entretanto, Sakkas et al..$^{38}$ e Voulvoulis et al..$^{59}$ reportaram concentrações de até 126 e 34,3 ng/g em sedimentos de marinas na Grécia e no estuário Blackwater, respectivamente.

A elevada toxicidade do Clorotalonil está diretamente relacionada à presença de múltiplos centros eletrofílicos reativos na molécula. Segundo vários trabalhos, espécies de água doce e salgada não mostram diferenças significativas entre os níveis de toxicidade para esse composto. ${ }^{60}$ Em testes de toxicidade realizados com espécies marinhas foi obtida para diatomácea $D$. tertiolecta uma $\mathrm{CE}_{50}(96 \mathrm{~h})$ de $64 \mu \mathrm{g} / \mathrm{L},{ }^{47}$ e para espécie de peixe Pimephales promelas foi observada uma $\mathrm{CL}_{50}\left(96 \mathrm{~h}\right.$ ) de 22,6 $\mu \mathrm{g} / \mathrm{L}$ (Tabela 3). ${ }^{47}$ Estes resultados sugerem uma toxicidade ligeiramente maior para espécies animais, fato que pode ser justificado pela forte interação do Clorotalonil com determinadas enzimas de respiração celular. ${ }^{61}$

A etapa de extração de Clorotalonil a partir de amostras de água utiliza usualmente EFS ou ELL. Para sedimentos, tem sido empregada a sonificação da amostra em solventes orgânicos, como acetona. A quantificação do composto é feita normalmente por CG com um detector de captura de elétrons (DCE). Porém, em virtude da sensibilidade, versatilidade e seletividade do CG/EM, essa técnica passou recentemente a ser bastante empregada. ${ }^{41}$

\section{Diclofluanida}

A Diclofluanida (N,N-Dimetil-N-fenil-N-(diclorofluorometilthio) sulfamida) pertence ao grupo químico dos organoclorados, apresenta uma baixa solubilidade em água $\left(0,006 \mathrm{mg} / \mathrm{L}\right.$ ) e um $\mathrm{K}_{\text {ow }}$ de 3,7 (Tabela 2). ${ }^{62} \mathrm{Em}$ razão das suas características físico-químicas, apresenta uma grande afinidade por material particulado e sedimentos. ${ }^{18}$ Além disso, em ambientes aquáticos com $\mathrm{pH}$ em torno de 8 , a Diclorofluanida tem sua tendência a adsorver ao material particulado e aos sedimentos aumentada. ${ }^{27}$ Esse composto mostra uma rápida taxa de degradação em água, apresentando uma meia vida de poucas horas nessa matriz. Ao se degradar, normalmente a Diclofluanida origina a N,N-Dimetilaminossulfanilida (DMSA), sendo que os principais fatores envolvidos são a concentração de matéria orgânica, o pH do meio, a atividade microbiana e a incidência de luz. ${ }^{63}$ Este biocida é também suscetível à degradação anaeróbica em sedimento, o que representa uma forma significativa de sua remoção do ambiente. ${ }^{27}$

A Diclofluanida não tem sido comumente detectada em amostras de água. Na Europa e na América do Norte, diversos estudos realizados com amostras de água obtidas em marinas e zonas portuárias encontraram concentrações inferiores aos limites de detecção das técnicas empregadas. ${ }^{38,58}$ Entretanto, concentrações de até $214 \mathrm{ng} / \mathrm{L}$ foram reportadas para algumas marinas na Grécia. ${ }^{18}$ Por outro lado, concentrações consideravelmente elevadas foram observadas em amostras de sedimentos costeiros oriundos de marinas. Em sedimentos obtidos no estuário de Blackwater (Inglaterra) foram determinadas concentrações de até $688 \mathrm{ng} / \mathrm{g}$, enquanto que na Ásia as concentrações variaram entre < 0,4 até $14 \mathrm{ng} / \mathrm{g}$ para a Baía Otsuchi (Japão) e entre $<0,1$ até $13 \mathrm{ng} / \mathrm{g}$ na costa do Vietnam. ${ }^{35}$ Adicionalmente, foram verificados picos de Diclofluanida imediatamente após as temporadas de intensa atividade náutica na Europa. Isso reforça a hipótese de uma fonte deste composto para o meio marinho estar ligada à utilização de tintas anti-incrustantes. ${ }^{24}$

No que diz respeito à toxicologia, em um estudo realizado por Bellas ${ }^{64}$ expondo larvas de três espécies de invertebrados marinhos à Diclofluanida, os valores de toxicidade obtidos para o molusco Mytulis edulis, o ouriço Paracentrotus lividus e o nematódeo Ciona intestinalis foram $\mathrm{CE}_{50}(48 \mathrm{~h})=81 \mu \mathrm{g} / \mathrm{L}, \mathrm{CE}_{50}(48 \mathrm{~h})=627 \mu \mathrm{g} / \mathrm{L} \mathrm{e}$ $\mathrm{CE}_{50}(24 \mathrm{~h})=283 \mu \mathrm{g} / \mathrm{L}$, respectivamente. Em outro estudo realizado com o micro-organismo Vibrio fisheri (15 min), a alga Selenastrum capricornotum (72 h) e o microcrustáceo Daphnia magna (48 h), os valores de $\mathrm{CE}_{50}$ observados foram de 15,7; 21 e $1.330 \mu \mathrm{g} / \mathrm{L}$, respectivamente (Tabela 3). ${ }^{65}$ Com base nesses resultados, e no fato de que a Diclofluanida apresenta acentuados efeitos carcinogênico e mutagênico, ${ }^{65}$ pode-se concluir que esse composto possui uma toxicidade mais elevada sobre organismos unicelulares, os quais apresentam ciclo de vida rápido. ${ }^{47}$

Os métodos de extração aplicados em matrizes ambientais para determinação do Diclofluanida geralmente são a EFS para água e a agitação mecânica com solventes orgânicos, como a acetonitrila, para sedimentos. ${ }^{35}$ A quantificação da Diclofluanida é normalmente realizada por CG acoplada a detectores seletivos, como o de captura de elétrons (DCE) ou espectrometria de massas em modo de ionização química negativa. ${ }^{41}$

\section{Tiram}

O Tiram (Tetrametiltiuramdissulfida) é um ditiocarbamato usado principalmente na agricultura como fungicida, no tratamento de folhas e sementes. Existem também registros de sua utilização na indústria de borracha, onde tem sido empregado como agente na vulcanização. Adicionalmente, a presença desse composto no ambiente pode ser também atribuída a processos de oxidação de dois outros fungicidas amplamente empregados: Derbam e Ziram. ${ }^{66} \mathrm{O}$ Tiram apresenta solubilidade moderada em água $(30 \mathrm{mg} / \mathrm{L})$ e um $\mathrm{K}_{\text {ow }}$ de 1,7 (Tabela 2$) .{ }^{27} \mathrm{~A}$ persistência do Tiram no ambiente aquático é fortemente influenciada pelo $\mathrm{pH}$ do meio, sendo degradado por hidrólise e fotólise. O tempo de meia vida deste composto é inferior a $24 \mathrm{~h} \mathrm{em} \mathrm{pH} \mathrm{9,} \mathrm{aumentando} \mathrm{para}$ 77 dias em pH 5. Já em relação à fotodegradação, o tempo de meia vida é de 8,8 h a um pH de 5,5, ou seja, sob irradiação solar o Tiram diminui significativamente sua persistência no ambiente aquático. ${ }^{53}$

Durante a realização do presente estudo não foram encontrados trabalhos reportando níveis de Tiram em amostras ambientais oriundas de ambientes aquáticos. Essa ausência de estudos ocorre possivelmente em virtude da sua rápida degradação nesse tipo de ambiente, dificultando a quantificação. ${ }^{67}$

Assim como ocorre com outros ditiocarbamatos, o Tiram apresenta níveis de toxicidade mais elevados para espécies de vertebrados como peixes, do que para invertebrados ou algas. Em dois estudos envolvendo testes de toxicidade com as espécies dulcícolas Chlorella pyrenoidosa (clorofícea), Daphnia magna (microcurstáceo) e Oncorhyncus mykiss (peixe), os valores obtidos foram de $1.000 \mu \mathrm{g} / \mathrm{L}$ $\left(\mathrm{CE}_{50} 96 \mathrm{~h}\right), 210 \mu \mathrm{g} / \mathrm{L}\left(\mathrm{CL}_{50} 48 \mathrm{~h}\right)$ e $0,64 \mu \mathrm{g} / \mathrm{L}\left(\mathrm{CE}_{50} 60\right.$ dias $)$, respectivamente (Tabela 3). ${ }^{68,69}$ Adicionalmente, vários trabalhos têm atestado as propriedades teratogênicas e mutagênicas do Tiram e de outros ditiocarbamatos. Entre as alterações subletais mais frequentemente induzidas por esse composto encontram-se as distorções na notocorda 
de embriões de peixes. Estas distorções acarretam deformidades na coluna vertebral ao final do desenvolvimento embrionário. ${ }^{70,71}$

Analiticamente, o Tiram pode ser determinado em matrizes ambientais através de técnicas de CG, empregando-se detectores como captura de elétrons (DCE), fotométrico de chama (DFC) e espectrometria de massa (EM). Adicionalmente, alguns estudos têm utilizado CLAE com detecção por ultravioleta (UV) para determinação analítica desse composto. ${ }^{72}$ Para preparação de amostras de água, a EFS e a ELL têm sido as técnicas preferencialmente aplicadas. ${ }^{73}$

\section{TCMTB (Busan)}

O biocida TCMTB (2-(tiocianometiltio) benzotiazol]) é um tiazol que, além de ser usado em formulações de tintas anti-incrustantes, tem sido aplicado como herbicida na agricultura e fungicida na preservação de madeira e na indústria de couro. ${ }^{27}$ Apresenta moderada solubilidade em água ( $45 \mathrm{mg} / \mathrm{L}$ ) e $\mathrm{K}_{\mathrm{ow}}$ de 3,3 (Tabela 2). Não existem até o momento estudos descrevendo o equilíbrio sortivo do TCMTB em meio aquático. ${ }^{60}$ Porém, em matrizes aquosas, esse composto se degrada rapidamente por fotólise (1,5 a 3,9 h). Essas características contribuem para a persistência extremamente baixa do TCMTB em ambientes aquáticos. A fotodegradação do TCMTB produz como principal metabólito o 2-mercaptobenzotiazol (MBT), apesar de traços de benzotiazol (BT) também serem originados no processo. A formação desses metabólitos, sobretudo o MBT, é especialmente importante para estudos de toxicidade ambiental do TCMTB. ${ }^{53}$

Poucos monitoramentos da ocorrência ambiental do TCMTB têm sido publicados na literatura especializada. Em um estudo realizado por Thomas et al., ${ }^{24}$ não foi detectada a presença de TCMTB em nenhum amostras de água e sedimentos oriundas de áreas portuárias e marinas do Reino Unido. O TCMTB também não foi detectado em amostras de água coletadas de marinas no sul da Espanha. ${ }^{54}$

De modo similar ao que se observa com relação a monitoramentos químicos do TCMTB, poucos estudos foram publicados sobre a toxicidade desse composto. Segundo Fernandez-Alba et al., ${ }^{65}$ o TCMTB atua como inibidor da cadeia de transporte de elétrons ao nível de mitocôndrias. Nesse mesmo estudo, testes de toxicidade realizados com o micro-organismo Vibrio fisheri, com o microcrustáceo Daphnia magna e com a alga Selenastrum capricornotum revelaram valores de $\mathrm{CE}_{50}$ equivalentes a $58 \mu \mathrm{g} / \mathrm{L}(15 \mathrm{~min}), 7,8 \mu \mathrm{g} / \mathrm{L}(30 \mathrm{~h})$ e $6,8 \mu \mathrm{g} / \mathrm{L}$ (48 h), respectivamente (Tabela 3 ).

Os métodos analíticos normalmente empregados para análise do biocida TCMTB em amostras ambientais são CL/EM e CG/EM. A extração do TCMTB a partir de matrizes aquosas é realizada através de EFS. Para amostras de sedimentos tem sido empregada a agitação mecânica em diclorometano. ${ }^{5}$

\section{TCMS Piridina (Densil)}

O TCMS Piridina ((2,3,3,6-tetracloro-4-metilsulfonil) piridina) passou a ser utilizado em formulações de tintas anti-incrustantes recentemente, porém esse composto era anteriormente empregado como fungicida na industria têxtil e de couros. ${ }^{40}$ Poucas informações sobre a físico-química do TCMS Piridina estão disponíveis na literatura especializada, entretanto, é sabido que sua solubilidade em água é extremamente baixa $(0,025 \mathrm{mg} / \mathrm{L})$.

Investigações realizadas sobre a ocorrência ambiental de novos biocidas utilizados em tintas anti-incrustantes detectaram traços de TCMS piridina em amostras ambientais de 4 diferentes estuários navegáveis do Reino Unido. As concentrações, entretanto, estavam abaixo dos limites de quantificação das técnicas empregadas. ${ }^{24}$

Do ponto de vista toxicológico o TCMS piridina é reconhecido como um potente inibidor da cadeia respiratória. Consequentemente, esse composto é capaz de bloquear a produção de trifosfato de adenosina (ATP) a nível mitocondrial, levando morte celular. ${ }^{74}$

Poucos trabalhos relatam metodologias analíticas para determinação do TCMS Piridina em amostras ambientais. Entretanto, Thomas ${ }^{55}$ descreve um método para determinação desse composto em amostras de água usando pré-concentração por EFS, eluição com acetonitrila e posterior quantificação por CL/EM com ionização química negativa à pressão atmosférica.

\section{Trifenilborano Piridina (TPBP)}

O Trifenilborano Piridina é conhecido desde 1960, sendo utilizado em produtos com atividade bactericida, antifúngica e anti-incrustantes. No Japão, a introdução do TPBP como agente anti-incrustante ocorreu em 1993. Poucas informações sobre a físico-química do TPBP estão disponíveis na literatura especializada, entretanto, sabe-se que sua solubilidade em água é relativamente baixa (aproximadamente, $1 \mathrm{mg} / \mathrm{L}){ }^{75}$ As vias de degradação do TPBP em água envolvem principalmente processos de hidrólise e fotólise. Experimentos realizados com diferentes concentrações de TPBP revelaram que esse composto apresenta uma meia vida inferior a 34 dias. Similarmente, os principais produtos de degradação do TPBP (Hidróxido de difenilborano (DPB), Hidróxido de fenilborano (MPB), fenol, benzeno e o difenil) apresentam uma persistência extremamente baixa em água. ${ }^{53}$

Possivelmente devido a sua rápida degradação e à formação de metabólitos pouco persistentes, poucos estudos relatam concentrações ambientais desse composto. O TPBP foi detectado em amostras de água obtidas na Baía de Hiroshima, no Japão. Entretanto, as concentrações foram inferiores ao limite de quantificação da técnica empregada. ${ }^{19}$

Praticamente inexistem estudos sobre a toxicologia do TPBP, exceção feita a um estudo onde a alga Skeletonema costatum $\left(\mathrm{CL}_{50}\right.$ $72 \mathrm{~h}=2,22 \mu \mathrm{g} / \mathrm{L}$ ) se mostrou mais sensível ao TPBP do que o microcrustáceo Artemia salina $\left(\mathrm{CL}_{50} 72 \mathrm{~h}=130 \mu \mathrm{g} / \mathrm{L}\right)$ (Tabela 3$)$. Neste mesmo estudo foi demonstrado também que os principais produtos de degradação do TPBP apresentam toxicidade bem inferior à do composto parental. ${ }^{76}$

A metodologia analítica normalmente empregada para determinação do TPBP utiliza pré-concentração por EFS, eluição com acetonitrila e a quantificação é realizada por CLAE acoplada a detector UV-visível (200 nm) e fluorescência. Não existem até o momento métodos de espectrometria de massas para determinação do TPBP. ${ }^{77}$

\section{BIOCIDAS METÁLICOS}

\section{Piritionas metálicas}

As piritionas metálicas à base de cobre e zinco são compostos que vêm sendo largamente utilizados como biocidas há mais de 50 anos. Zinco Piritiona (Zinco, bis-(hidroxi-2(H)-piridinationato-O,S)), por exemplo, tem sido utilizado na agricultura como bactericida e fungicida, e na indústria de cosméticos em produtos com atividade anticaspa, como xampus. Já o composto Cobre Piritiona (Cobre, bis(1,hidroxi-2(1H)-piridinationato-O,S)) possui aplicações como bactericida e fungicida. ${ }^{78}$

Um aspecto marcante do comportamento ambiental do Zinco Piritiona (ZP) é sua grande susceptibilidade a sofrer reações de transquelação com cobre, ferro e, possivelmente, com manganês. Sendo assim, dependendo das concentrações disponíveis desses íons metálicos na água e nos sedimentos, ZP converte-se em Cobre Piritiona (CP). ${ }^{29}$ Apesar disso, todos os complexos metálicos de piritionas são extremamente sensíveis à luz, sofrendo rápida dimerização por fotodegradação. Estudos experimentais demonstraram que, sob irradiação 
UV, a meia vida do CP é de aproximadamente $29 \mathrm{~min}$, enquanto que a do ZP é de 15 min. ${ }^{53}$ Adicionalmente, esses compostos também sofrem degradação por hidrólise e por atividade microbiana, tornando suas meias vidas nos ambientes marinhos ainda mais curtas. ${ }^{29,79}$ Devido à baixa disponibilidade de dados sobre sua ocorrência ambiental, o comportamento de sorção das piritionas metálicas é até o momento desconhecido. ${ }^{27}$ Entretanto, a maior solubilidade do ZP (6 mg/L) em relação ao $\mathrm{CP}(<1 \mathrm{mg} / \mathrm{L})$ sugere que esses compostos particionam preferencialmente em compartimentos ambientais distintos. Dessa forma, é mais provável encontrar resíduos de $\mathrm{ZP}$ em amostras de água, enquanto que para $\mathrm{CP}$ os sedimentos tendem a ser a matriz mais indicada para realização de monitoramentos.

Poucos monitoramentos têm sido realizados para piritionas metálicas no mundo. Em um único estudo conduzido por Thomas et al., ${ }^{45}$ concentrações de até $20 \mathrm{ng} / \mathrm{L}$ de $\mathrm{ZP}$ foram detectadas em amostras de água coletadas em marinas do Reino Unido. Já as concentrações de CP, em um estudo realizado em sedimentos obtidos nas proximidades de áreas portuárias da costa norte do Vietnã, variaram entre $<$ LQ (inferiores ao limite de quantificação da técnica) e $422 \mathrm{ng} / \mathrm{g}$, encontrado em uma das estações situada nas proximidades de um terminal pesqueiro. ${ }^{80} \mathrm{Em}$ outro estudo realizado na costa do Japão, concentrações máximas de 8,6 ng/g de CP foram encontradas na baía de Otsushi. ${ }^{35}$ A escassez de dados sobre a ocorrência ambiental do $\mathrm{CP}$ e do $\mathrm{ZP}$ ocorre, possivelmente, devido à elevada degradabilidade desses compostos, bem como pelas dificuldades analíticas enfrentadas durante sua determinação.

Diversos estudos sobre a toxicidade do CP e do ZP sobre organismos aquáticos têm sido publicados. Em crustáceos, os valores de $\mathrm{CL}_{50}$ para as piritionas metálicas são geralmente superiores a $100 \mu \mathrm{g} / \mathrm{L}$ (Tabela 3). ${ }^{47}$ Particularmente no caso do camarão Heptacarpus futilirustris, a $\mathrm{CL}_{50}(96 \mathrm{~h})$ observada para $\mathrm{ZP}$ foi excepcionalmente elevada $(2,5 \mu \mathrm{g} / \mathrm{L}) .{ }^{47}$ Entretanto, a toxicidade do ZP e CP para espécies fitoplanctônicas e de peixes se mostra maior que para crustáceos. Segundo Mochida e Fuji, ${ }^{47}$ a elevada toxicidade das piritionas metálicas sobre espécies de peixes se justifica pela sua ação potente como inibidoras do transporte de membrana, que afeta diretamente a bomba de prótons necessária à respiração celular. No caso específico do $\mathrm{CP}$ ocorre um bloqueio da atividade neuromuscular, a qual é imprescindível durante o desenvolvimento embrionário desses organismos. Como consequência desses efeitos subletais, surgem deformações esqueléticas e formação de massas inflamatórias em peixes expostos por períodos de 50 dias a concentrações nominais de 2 a $4 \mu \mathrm{g} / \mathrm{L}$ desses compostos.

De modo geral, complexos metálicos de piritiona não são determinados por CG devido à sua baixa volatilidade e alta instabilidade térmica ${ }^{81}$ Dessa forma, as técnicas universalmente empregadas na determinação desses compostos em matrizes ambientais utilizam CL/ EM com modo de ionização química à pressão atmosférica. Devido à tendência do ZP a sofrer transquelação em meios onde existam íons metálicos disponíveis, alguns métodos empregados na determinação desse composto induzem essa reação no intuito de formar moléculas mais estáveis e minimizar perdas durante as etapas de análise. ${ }^{78}$ As técnicas de extração usualmente empregadas para amostras ambientais são EFS e agitação mecânica com solventes orgânicos para amostras de água e sedimentos, respectivamente. ${ }^{82}$

\section{Ziram}

O Ziram (Zinco dimetilditiocarbamato) é um ditiocarbamato que é utilizado atualmente como fungicida agrícola, para proteção de frutos e sementes, e como catalisador do processo de vulcanização e antioxidante na indústria de borracha. ${ }^{83}$ Apresenta moderada solubilidade em água $(17 \mathrm{mg} / \mathrm{L})$ e um $\mathrm{K}_{\text {ow }}$ extremamente baixo $(1,23) .{ }^{53}$ Em virtude de suas propriedades físico-químicas e de ser extremamente suscetível aos processos de hidrólise, fotólise e biodegradação, o tempo de meia vida do Ziram em ambientes marinhos é de, no máximo, 18 dias. ${ }^{60}$

Embora existam alguns estudos onde se realizaram monitoramentos do Ziram em amostras ambientais, nenhum destes relaciona a ocorrência do composto a sua nova utilização como princípio ativo em tintas anti-incrustantes. ${ }^{60,83}$

Assim como outros ditiocarbamatos, o Ziram exibe uma forte toxicidade sobre os estágios iniciais do desenvolvimento larval de peixes, sendo a deformação da notocorda o efeito mais frequentemente observado. Para a espécie de peixe dulcícola Oncorhynchus mykiss, por exemplo, a $\mathrm{CE}_{50}$ (60 dias) observada para esse composto foi de $1,5 \mu \mathrm{g} / \mathrm{L}$. Por outro lado, a $\mathrm{CE}_{50}(96 \mathrm{~h})$ obtida para alga $C$. pyrenoidosa foi de $1.200 \mu \mathrm{g} / \mathrm{L}$ (Tabela 3). ${ }^{71}$ Embora ainda não existam dados de toxicidade ao Ziram disponíveis para espécies de água salgada, esses resultados ilustram claramente a já mencionada sensibilidade das espécies de peixes a ditiocarbamatos.

A maioria dos métodos para determinação de ditiocarbamatos envolve a decomposição prévia dos analitos de interesse em dissulfeto de carbono ou derivatização para metiltiocarbamatos, com posterior determinação por técnicas cromatográficas (CG ou CL). Esses métodos, entretanto, têm baixa seletividade devido às similaridades entre os diversos ditiocarbamatos. Sendo assim, foi desenvolvido recentemente um novo método para determinação direta do Ziram (sem derivatização) por CL/EM com modo de ionização química positiva à pressão atmosférica. ${ }^{84} \mathrm{~A}$ EFS e a ELL são normalmente empregadas para extração do Ziram a partir de amostras de água. ${ }^{73}$

\section{Maneb}

O Maneb ([etileno-bis-(ditiocarbamato)manganês]polimérico) é um ditiocarbamato polimérico que, além de ser utilizado em tintas anti-incrustantes, também possui aplicações na agricultura como fungicida. Embora seja um composto moderadamente solúvel em água $(6 \mathrm{mg} / \mathrm{L})^{85}$ estudos experimentais revelaram que ele se decompõe rapidamente nessa matriz, através de hidrólise e fotólise. Adicionalmente, a degradação biológica tem pouca importância no seu comportamento ambiental..$^{5}$ Segundo esses estudos, a persistência do Maneb no ambiente é aproximadamente 10,5 h. Os principais produtos de degradação do Maneb são a etilenoureia, o etileno bis isotiocianatossulfida e a carbamida. , $53^{5,53}$

Algumas possíveis técnicas analíticas para determinação do Maneb em amostras ambientais foram discutidas por Voulvoulis et $a l .{ }^{86}$ porém ainda não existem métodos para sua determinação rotineira. ${ }^{5} \mathrm{O}$ principal desafio analítico enfrentado para determinação desse composto é a seletividade do método. Isso ocorre em função do fato de existirem compostos estruturalmente semelhantes ao Maneb, como é o caso do Zineb (zinco etileno bis (ditiocarbamato)), o qual também é um ditiocarbamato que tem aplicações na agricultura e em alguns produtos anti-incrustantes. Sendo assim, um método para determinação do Maneb em amostras ambientais deve ser capaz de diferenciá-lo de compostos similares que, eventualmente, podem está concomitantemente presentes nas amostras. Uma das soluções apontadas para esse problema seria a realização de uma análise paralela por espectrometria de absorção atômica a fim de diferenciar o magnésio do zinco, permitindo a discriminação entre o Maneb e o Zineb. ${ }^{40}$

\section{Biocidas à base de cobre}

Os compostos cúpricos atualmente homologados pela IMO para utilização em tintas náuticas são: Óxido Cuproso $\left(\mathrm{Cu}_{2} \mathrm{O}\right)$, Tiocianato de Cobre (CuSCN) e Naftenato de Cobre. ${ }^{14} \mathrm{O}$ emprego desses compostos ocorreu após o banimento mundial dos anti-incrustantes à base de COE. Nessa época, diversos produtos 
voltaram a incorporar em suas formulações grandes quantidades de compostos à base de cobre e/ou cobre metálico, com a finalidade de incrementar o efeito biocida dessas novas tintas. Sendo assim, a maioria dos produtos disponíveis no mercado mundial atualmente utiliza o cobre associado a um ou mais dos biocidas mencionados anteriormente. Dessa forma, devido ao amplo espectro de toxicidade do cobre sobre organismos aquáticos, os demais compostos atuam como intensificadores do efeito biocida. ${ }^{87}$

A taxa de liberação do cobre contido em um revestimento antiincrustante para coluna d'água está relacionada a diversos fatores de natureza física, química e biológica. ${ }^{87}$ Adicionalmente, os níveis naturais desse elemento na coluna d'água e nos sedimentos não são conhecidos para muitas regiões. Sendo assim, avaliações realísticas sobre a contribuição das tintas anti-incrustantes para as concentrações de cobre observadas em zonas com intensa atividade naval são difíceis de serem realizadas. Porém, diferenças significativas nas concentrações de cobre em sedimentos foram observadas entre áreas navegadas e não navegadas do Reino Unido. Nesse estudo, as concentrações verificadas em áreas relativamente pouco impactadas estavam entre 1 e $10 \mu \mathrm{g} / \mathrm{g}$, enquanto que em áreas historicamente navegadas encontraram-se valores de até $3.000 \mu \mathrm{g} / \mathrm{g} .{ }^{88}$

A toxicidade do cobre para organismos aquáticos está vinculada a fatores físico-químicos como $\mathrm{pH}$, salinidade, teor de carbono orgânico dissolvido e concentração do metal. Isso ocorre em virtude da tendência desse elemento em sofrer especiação, originando diferentes formas químicas de acordo com as características físico-químicas do ambiente, podendo estar na forma livre, ionizada ou até mesmo formar complexos com ligantes orgânicos e inorgânicos. Dessa forma, as diferentes espécies de cobre apresentaram biodisponibilidades e, consequentemente, toxicidades diferentes ${ }^{87}$

\section{CONSIDERAÇÕES FINAIS}

Dentre os 16 compostos apresentados no presente trabalho, o Irgarol 1051, Diuron, Sea-Nine (DCOIT), Clorotalonil, Diclofluanida, Zinco Piritiona, Cobre Piritiona e Óxido Cuproso possuem mecanismos de toxicidade e comportamento ambiental razoavelmente bem compreendidos. ${ }^{89}$ Por outro lado, Tiram, Busan (TCMTB), TCMS Piridina e Trifenilbornano Piridina, Ziram, Maneb, Tiocianato de Cobre e Naftenato de Cobre são compostos proporcionalmente menos empregados nas tintas, havendo pouca informação disponível na literatura especializada. Além disso, outros compostos são atualmente relacionados como possíveis candidatos a serem incorporados em sistemas anti-incrustrantes, entre eles a "Econea" (CAS 122454-29-9), Medetomidina (CAS 106807-72-1) e Capsaicina (CAS 8023-77-6). ${ }^{89}$

\section{Características ideais de um anti-incrustante}

$\mathrm{Na}$ busca pelo anti-incrustante de alto desempenho, a indústria naval tem procurado equilibrar a eficiência e a durabilidade dos novos produtos com níveis de toxicidade ambientalmente toleráveis. Com foco nesse objetivo, Takahashi ${ }^{52}$ argumenta que os compostos de ação anti-incrustante ideal devem apresentar as seguintes características: amplo espectro de ação, a fim de prevenir com eficiência o estabelecimento das várias espécies de organismos que iniciam a formação do biofilme incrustante; baixa toxicidade para mamíferos; baixa solubilidade em água; baixo potencial de bioacumulação e biomagnificação; baixa ou nenhuma persistência ambiental; serem compatíveis com os equipamentos e técnicas de pintura atualmente em uso e, custos e durabilidade competitivos com os produtos atualmente disponíveis no mercado.

Nesse aspecto, a prospecção de compostos pouco persistentes, com baixa toxidade ambiental e que incorporem revestimentos efi- cientes e de alta durabilidade é uma tarefa difícil, devido às características conflitantes requeridas por um anti-incrustante considerado ideal. ${ }^{29}$ Entretanto, entre os biocidas utilizados em tintas de terceira geração despontam alguns candidatos em potencial, visto que alguns destes atendem razoavelmente às exigências, principalmente se comparados aos compostos utilizados em tintas de segunda geração (como o TBT e o TPT). Dentre os compostos que melhor atendem tais exigências, o DCOIT (componente ativo do Sea-Nine) tem recebido especial atenção, em função de sua elevada eficiência combinada com rápida degradação no ambiente. ${ }^{51}$

\section{Avaliações ecotoxicológicas}

Do ponto de vista ecotoxicológico, a utilização simultânea de diversos produtos com atividade biocida nas tintas de terceira geração representa uma dificuldade suplementar à realização de experimentos que simulem condições realísticas. Mesmo assim, estudos do efeito de diferentes combinações de biocidas utilizados nas novas formulações têm sido realizados pela exposição simultânea a organismos teste. Foram observados, por exemplo, efeitos sinérgicos e aditivos entre combinações de 2 e 3 compostos diferentes..$^{90}$ Porém, é muito difícil realizar avaliações precisas, na medida que algumas tintas podem conter até 4 diferentes agentes tóxicos na sua composição ${ }^{14}$ e que, em uma mesma marina ou porto, trafegam embarcações que utilizam produtos distintos. Somam-se a isso, os demais compostos que constituem as tintas, assim como a interação com inúmeros outros contaminantes já presentes nestes ambientes, o que resulta em uma mistura extremamente complexas de analitos.

Alternativamente, experimentos foram concebidos a fim de realizar exposição de organismos teste diretamente às tintas antiincrustantes e não somente aos biocidas nelas presentes. Nesse aspecto, o trabalho realizado por Karlsson et al. ${ }^{91}$ com a macroalga Ceramium tenuicorne e o copépode Nitocra spinipes merece especial atenção. Nesse estudo, os autores pintaram placas de plástico de $5 \mathrm{~cm}^{2}$ com diferentes produtos destinados a embarcações que trafegam no Mar Báltico. Estas placas foram então submersas em água do mar artificial por diferentes períodos, a qual foi posteriormente utilizada como solução teste nos experimentos de exposição. Com essa abordagem, Karlsson e colaboradores desenvolveram uma técnica capaz de avaliar simultaneamente os efeitos tóxicos da complexa matriz que representam as tintas anti-incrustantes. Apesar das limitações iniciais, experimentos que tentam melhor reproduzir a realidade da exposição representam um avanço e são uma alternativa aos que não levam em consideração a interação na exposição simultânea a diversos compostos.

\section{Determinações analíticas}

Estudos sobre toxicidade, ocorrência e comportamento ambiental de biocidas utilizados em tintas anti-incrustantes requerem métodos robustos e capazes de determinar simultaneamente esses compostos em amostras ambientais. A grande diversidade de propriedades físico-químicas e a profusão de metabólitos de interesse, que podem se formar no ambiente, contribuem substancialmente para dificultar o desenvolvimento de uma metodologia que atenda estes requisitos. Entretanto, alguns métodos simultâneos de determinação têm sido publicados na literatura especializada. Por exemplo, Thomas ${ }^{55}$ descreve um método analítico capaz de determinar simultâneamente Irgarol 1051, Diuron, Sea-Nine, TCMS piridina e TCMTB. Essa técnica utiliza EFS (com cartuchos de C18 e polimérico) e detecção por CL/EM com ionização química à pressão atmosférica. Similarmente, o método proposto por Aguerra el al..$^{54}$ determina Irgarol 1051, Diuron, Sea-Nine, TCMTB, Clorotalonil e Diclorofluanida, em uma única injeção, por CG/EM. 
Entretanto, alguns compostos como as Piritionas metálicas (ZP e CP) e os dtiocarbamatos (Tiram, Ziram e Maneb) apresentam propriedades fisico-químicas intrínsecas, as quais dificultam sua análise juntamente com outros compostos. Dessa forma, o desenvolvimento e validação de um método de quantificação multirresíduo para os 16 biocidas homologados para utilização em tintas anti-incrustantes de terceira geração representa ainda um grande desafio analítico. ${ }^{5}$

\section{PERSPECTIVAS}

Em virtude da constante pressão internacional sobre a utilização de tintas anti-incrustantes, a indústria naval tem frequentemente buscado alternativas ambientalmente amigáveis. Entre essas iniciativas destacam-se o desenvolvimento de tintas anti-incrustantes à base de produtos naturais e os revestimentos livres de biocidas.

Muitos organismos produzem naturalmente substâncias com atividade anti-incrustante, a fim de prevenir a colonização dos seus próprios corpos por biofilmes de organismos. Esses produtos naturais pertencem a diferentes grupos químicos como terpenos, compostos nitrogenados, fenóis, esteroides, dentre outros. Estudos preliminares indicam que algumas dessas substâncias apresentam atividade anti-incrustante tão satisfatória quanto a observada em compostos organoestânicos. Sendo assim, existe uma forte expectativa de se utilizar, no futuro, esses compostos como ingrediente ativo em tintas anti-incrustantes. ${ }^{92}$ Nesse contexto, alguns estudos no Brasil têm indicado que determinadas espécies de macroalgas vermelhas produzem metabólitos com elevada atividade anti-incrustante. Esses metabólitos podem, no futuro, ser utilizados como ingredientes ativos em tintas náuticas..$^{93}$

Outra abordagem que vem sendo testada recentemente é a aplicação de anti-incrustantes livres de biocidas. Esses revestimentos apresentam um mecanismo de ação totalmente diferente das tintas anti-incrustantes tradicionais. Eles atuam essencialmente por meio da formação de uma barreira extremamente lisa, que dificulta a aderência de organismos aquáticos, favorecendo sua remoção natural durante o deslocamento da embarcação. Constituídos principalmente de polímeros de flúor (teflon) e silicones, os revestimentos livres de biocidas têm se mostrado eficientes para embarcações velozes (>21 nós). Entretanto, sua durabilidade é inferior a 3 anos para embarcações mais lentas, o que inviabiliza comercialmente sua aplicação em embarcações de grande porte. ${ }^{2}$ Adicionalmente, alguns estudos demonstraram experimentalmente a liberação de compostos indesejáveis, bem como efeitos tóxicos relacionados a esses novos tipos de revestimento. ${ }^{94}$

\section{RECOMENDAÇÕES FINAIS}

O desenvolvimento de métodos analíticos robustos, capazes de determinar simultaneamente e com precisão os níveis dos compostos anti-incrustantes de $3^{a}$ geração em amostras ambientais é, sem dúvida, uma das grandes necessidades globais relacionadas à avaliação do seu impacto. Concomitantemente ao desenvolvimento dessas metodologias, é fundamental que sejam identificadas as áreas mais suscetíveis à contaminação e viabilizados estudos de monitoramento das áreas mais passíveis a impacto (ex.: importante atividade de navegação e circulação restrita). Esta questão é especialmente delicada em se tratando de regiões como a América do Sul, em razão da quase inexistência de estudos dessa natureza.

Além disso, precisam ser realizadas avaliações ecotoxicológicas mais realísticas, envolvendo, principalmente, a exposição de organismos nativos a misturas de biocidas e/ou às próprias tintas, no intuito de se obter avaliações de risco mais condizentes com a realidade e particularidades de cada região. Da mesma forma que estudos ecoto- xicológicos devem ser integrados a dados de ocorrência ambiental, a fim de avaliar a possível extensão dos danos causados pela utilização destes produtos. Esta é a melhor forma de subsidiar a implementação de medidas regulatórias ou de gestão, as quais, quando necessário, envolvem ações restritivas e/ou mitigadoras, a exemplo do que já acontece em países europeus e asiáticos. ${ }^{26}$

\section{REFERÊNCIAS}

1. Yebra, D. M.; Kiil, S.; Dam-Johansen, K.; Prog. Org. Coat. 2004, 50, 75 .

2. Almeida, E.; Diamantino, T. C.; de Sousa, O.; Prog. Org. Coat. 2007, $59,2$.

3. Kotrikla, A.; J. Environ. Manag. 2009, 90, S77.

4. Godoi, A. F. L.; Favoreto, R.; Santiago-Silva, M.; Quim. Nova 2003, 26, 708.

5. Fernandez, M. A.; Pinheiro, F.; Int. J. Environ. Health 2007, 1, 427.

6. Fent, K.; Toxicol. Lett. 2003, 140-141, 353.

7. Alzieu, C.; Heral, M.; Thibaud, Y.; Dardignac, M.; Feuillet, M.; Rev. Inst. Péches Maritime 1982, 45, 101.

8. Alzieu, C.; Sci. Total Environ. 2000, 258, 99.

9. Ketata, I.; Denier, X.; Hamza-Chaffai, A.; Minier, C.; Comp. Biochem. Physiol., Part C: Toxicol. Pharmacol. 2008, 147, 261.

10. Sonak, S.; J. Environ. Manag. 2009, 90, S1.

11. Sonak, S.; Pangam, P.; Giriyan, A.; Hawaldar, K.; J. Environ. Manag. 2009, 90, S96.

12. Shi, H. H.; Huang, C. J.; Zhu, X. S.; Yu, X. J.; Xie, W. Y.; Mar. Ecol. Prog. Ser. 2005, 304, 179.

13. IMO; Antifouling Systems, International Convention on the Control of Harmful Anti-fouling Systems on Ships, International Maritime Organization: London, 2005.

14. Okamura, H.; Mieno, H. Em Handbook of Environmental Chemistry: Antifouling Paints Biocides; Konstantinou, I. K., ed.; Springer-Verlag: Berlin, 2006, cap. 9.

15. Albanis, T. A.; Lambropoulou, D. A.; Sakkas, V. A.; Konstantinou, I. K.; Chemosphere 2002, 48, 475.

16. Mukherjee, A.; Mohan Rao, K. V.; Ramesh, U. S.; J. Environ. Manag. 2009, 90, S51.

17. Gatidou, G.; Thomaidis, N. S.; Zhou, J. L.; Environ. Int. 2007, 33, 70.

18. Thomas, K. V.; Langford, K. H. Em Ecotoxicology of Antifouling Biocides; Arai, T.; Harino, H.; Ohji, M., Langston, W. J., eds.; Springer: Tokio, 2009, cap. 19.

19. Harino, H.; Arai, T.; Ohji, M.; Nobuyuki, M. Em ref. 18, cap. 20.

20. Demoliner, A.; Caldas, S. S.; Costa, F. P.; Gonçalves, F. F.; Clementin, R. M.; Milani, M. R.; Primel, E.; J. Braz. Chem. Soc. 2010, 21, 1424.

21. Azevedo, D. D.; Gerchon, E.; Reis, E. O.; J. Braz. Chem. Soc. 2004, 15, 292.

22. Okamura, H.; Sugiyama, Y.; Chemosphere 2004, 57, 739.

23. Okamura, H.; Aoyama, I.; Takami, T.; Maruyama, T.; Suzuki, Y.; Matsumoto, M.; Katsuyama, I.; Hamada, J.; Beppu, T.; Tanaka, O.; Maguire, R. J.; Liu, D.; Lau, Y. L.; Pacepavicius, G. J.; Mar. Pollut. Bull. 2000, 40, 754.

24. Thomas, K. V.; McHugh, M.; Waldock, M.; Sci. Total Environ. 2002, $293,117$.

25. Lam, K. H.; Wai, H. Y.; Leung, K. M. Y.; Tsang, V. W. H.; Tang, C. F.; Cheung, R. Y. H.; Lam, M. H. W.; Chemosphere 2006, 64, 1177.

26. Readman, J. Em ref. 14, cap. 1.

27. Voulvoulis, N. Em ref. 14, cap. 7.

28. Basheer, C.; Tan, K. S.; Lee, H. K.; Mar. Pollut. Bull. 2002, 44, 697.

29. Harino, H.; Langston, W. J. Em ref. 18, cap. 23.

30. Gardinali, P. R.; Plasencia, M. D.; Maxey, C.; Mar. Pollut. Bull. 2004, 49, 1072

31. Ferrer, I.; Barcelo, D.; J. Chromatogr., A 2001, 926, 221. 
32. Martinez, K.; Ferrer, I.; Barceló, D.; J. Chromatogr., A 2000, 879, 27.

33. Gough, M. A.; Fothergill, J.; Hendrie, J. D.; Mar. Pollut. Bull. 1994, 28, 613.

34. Bowman, J. C.; Readman, J. W.; Zhou, J. L.; Mar. Pollut. Bull. 2003, 46, 444.

35. Harino, H.; Yamamoto, Y.; Eguchi, S.; Kawai, S.; Kurokawa, Y.; Arai, T.; Ohji, M.; Okamura, H.; Miyazaki, N.; Arch. Environ. Cont. Toxicol. 2007, 52, 179.

36. Dominguez, L. A.; Tese de Doutorado, Universidade Federal do Rio Grande, Brasil, 2010.

37. Hall, L. W.; Giddings, J. M.; Solomon, K. R.; Balcomb, R.; Crit. Rev. Toxicol. 1999, 29, 367.

38. Sakkas, V. A.; Lambropoulou, D. A.; Albanis, T. A.; J. Photochem. Photobiol., A 2002, 147, 135.

39. Perina, F. C.; Dissertação de Mestrado, Universidade Federal do Rio Grande, Brasil, 2009.

40. Voulvoulis, N.; Scrimshaw, M. D.; Lester, J. N.; Chemosphere 1999, 38 , 3503.

41. Hernando, M.; Mezcua, M.; Barcelo, D.; Fernandez-Alba, A. R. Em ref. 14, cap. 6.

42. Ferrer, I.; Ballesteros, B.; Marco, M. P.; Barcelo, D.; Environ. Sci. Technol. 1997, 31, 3530.

43. Thomas, K. V.; Blake, S. J.; Waldock, M. J.; Mar. Pollut. Bull. 2000, 40, 739.

44. Lamoree, M. H.; Swart, C. P.; van der Horst, A.; van Hattum, B.; J. Chromatogr., A 2002, 970, 183.

45. Thomas, K. V.; Fileman, T. W.; Readman, J. W.; Waldock, M. J.; Mar. Pollut. Bull. 2001, 42, 677.

46. Konstantinou, I. K.; Albanis, T. A.; Environ. Int. 2004, 30, 235.

47. Mochida, K.; Fujii, K. Em ref. 18, cap. 22.

48. Manzo, S.; Buono, S.; Cremisini, C.; Arch. Environ. Cont. Toxicol. 2006, $51,61$.

49. Harino, H.; Yamamoto, Y.; Eguchi, S.; Kawai, S.; Kurokawa, Y.; Arai, T.; Ohji, M.; Okamura, H.; Miyazaki, N.; Arch. Environ. Cont. Toxicol. 2007, 52, 179 .

50. Gerecke, A. C.; Tixier, C.; Bartels, T.; Schwarzenbach, R. P.; Muller, S. R.; J. Chromatogr., A 2001, 930, 9.

51. Jacobson, A. H.; Willingham, G. L.; Sci. Total Environ. 2000, 258, 103.

52. Takahashi, K. Em ref. 18, cap. 1.

53. Sakkas, V. A.; Konstantinou, I. K.; Albanis, T. A. Em ref. 14, cap. 8.

54. Aguera, A.; Piedra, L.; Hernando, M. D.; Fernandez-Alba, A. R.; J. Chromatogr., A 2000, 889, 261.

55. Thomas, K. V.; J. Chromatogr., A 1998, 825, 29.

56. Walker, W. W.; Cripe, C. R.; Pritchard, P. H.; Bourquin, A. W.; Chemosphere 1988, 17, 2255.

57. Walker, A.; Jurado-Exposito, M.; Weed Res. 1998, 38, 229.

58. Carbery, K.; Owen, R.; Frickers, T.; Otero, E.; Readman, J.; Mar. Pollut. Bull. 2006, 52, 635.

59. Vouvoulis, N.; Scrimshaw, M. D.; Lester, J. N.; Mar. Pollut. Bull. 2000, 40, 938.

60. van Wezel, A. P.; van Vlaardingen, P.; Aquat. Toxicol. 2004, 66, 427.

61. Caux, P. Y.; Kent, R. A.; Fan, G. T.; Stephenson, G. L.; Crit. Rev. Environ. Sci. Technol. 1996, 26, 45.

62. Hamwijk, C.; Schouten, A.; Foekema, E. M.; Ravensberg, J. C.; Collombon, M. T.; Schmidt, K.; Kugler, M.; Chemosphere 2005, 60, 1316.
63. Sakkas, V. A.; Konstantinou, I. K.; Albanis, T. A.; J. Chromatogr., A 2001, 930, 135 .

64. Bellas, J.; Sci. Total Environ. 2006, 367, 573.

65. Fernandez-Alba, A. R.; Hernando, M. D.; Piedra, L.; Chisti, Y.; Anal. Chim. Acta 2002, 456, 303.

66. Cereser, C.; Boget, S.; Parvaz, P.; Revol, A.; Toxicology 2001, 162, 89.

67. Samanidou, V.; Fytianos, K.; Pfister, G.; Bahadir, M.; Sci. Total Environ. 1988, 76, 85 .

68. van Leeuwen, C. J.; Maas-Diepeveen, J. L.; Niebeek, G.; Vergouw, W. H. A.; Griffioen, P. S.; Luijken, M. W.; Aquat. Toxicol. 1985, 7, 145.

69. van Leeuwen, C. J.; Moberts, F.; Niebeek, G.; Aquat. Toxicol. 1985, 7, 165.

70. van Leeuwen, C. J.; Helder, T.; Seinen, W.; Aquat. Toxicol. 1986, 9, 147.

71. van Leeuwen, C. J.; Espeldoorn, A.; Mol, F.; Aquat. Toxicol. 1986, 9, 129.

72. Crnogorac, G.; Schwack, W.; TrAC, Trends Anal. Chem. 2009, $28,40$.

73. Kawamoto, T.; Yano, M.; Makihata, N.; J. Chromatogr., A 2005, 1074, 155.

74. Bragadin, M.; Iero, A.; Cima, F.; Ballarin, L.; Manente, S.; Toxicol. in Vitro 2007, 21, 1127.

75. Harino, H.; Coastal Marine Science 2004, 29, 28.

76. Okamura, H.; Kitano, S.; Toyota, S.; Harino, H.; Thomas, K. V.; Chemosphere 2009, 74, 1275.

77. Zhou, X.; Okamura, H.; Nagata, S.; Chemosphere 2007, 67, 1904.

78. Doose, C. A.; Szaleniec, M.; Behrend, P.; Muller, A.; Jastorff, B.; J. Chromatogr., A 2004, 1052, 103.

79. Maraldo, K.; Dahllof, I.; Mar. Pollut. Bull. 2004, 48, 894.

80. Harino, H.; Ohji, M.; Wattayakorn, G.; Arai, T.; Rungsupa, S.; Miyazaki, N.; Arch. Environ. Cont. Toxicol. 2006, 51, 400.

81. Karlsson, J.; Eklund, B.; Mar. Pollut. Bull. 2004, 49, 456.

82. Harino, H.; Midorikawa, S.; Arai, T.; Ohji, M.; Cu, N. D.; Miyazaki, N.; J. Mar. Biol. Ass. U. K. 2006, 86, 1163.

83. Agarwal, S.; Aggarwal, S. G.; Singh, P.; Talanta 2005, 65, 104.

84. Moriwaki, H.; Yukihiko, Y.; Minoru, F.; Rapid Commun. Mass Spectrom. 2001, 15, 2374.

85. Thiruchelvam, M. Em Encyclopedia of Toxicology; Philip, W., ed.; Elsevier: New York, 2005.

86. Voulvoulis, N.; Scrimshaw, M. D.; Lester, J. N.; Chemosphere 1999, 38, 3503.

87. Brooks, S. J.; Waldock, M. Em ref. 18, cap. 24.

88. Jones, B.; Bolam, T.; Mar. Pollut. Bull. 2007, 54, 1127.

89. Thomas, K. V.; Brooks, S.; Biofouling 2010, 26, 73.

90. Koutsaftis, A.; Aoyama, I.; Sci. Total Environ. 2007, 387, 166.

91. Karlsson, J.; Breitholtz, M.; Eklund, B.; Mar. Pollut. Bull. 2006, 52, 1661.

92. Omae, I. Em ref. 14, cap. 12.

93. da Gama, B. A. P.; Carvalho, A. G. V.; Weidner, K.; Soares, A. R.; Coutinho, R.; Fleury, B. G.; Teixeira, V. L.; Pereira, R. C.; Botanica Marina 2008, 51, 191.

94. Watermann, B. T.; Daehne, B.; Sievers, S.; Dannenberg, R.; Overbeke, J. C.; Klijnstra, J. W.; Heemken, O.; Chemosphere 2005, 60, 1530.

95. Lambropoulou, D. A.; Sakkas, V. A.; Albanis, T. A.; Int. J. Environ. Anal. Chem. 2004, 84, 47. 